\title{
Determinants of Maternal Care Services Utilization within Conjugal Context in Lagos State
}

\author{
Felicia A. Oyekanmi", Kennedy Eborka, Olusegun Temilola \\ Department of Sociology, Faculty of Social Sciences, University of Lagos, Nigeria
}

Copyright $\mathrm{O} 2018$ by authors, all rights reserved. Authors agree that this article remains permanently open access under the terms of the Creative Commons Attribution License 4.0 International License

\begin{abstract}
Antenatal care attendance is an essential component of maternal health and critical to reducing high maternal and child mortality in Nigeria. This study focused on factors that influence maternal healthcare services utilization at the conjugal level. The study was carried out among ever-married men and women in Shomolu, Lagos State, between March and June, 2017. Both quantitative and qualitative approaches were adopted to implement the study. At the quantitative level, cross-sectional survey was adopted while In-Depth Interview (IDI) was used at the qualitative level. The probability sampling technique was adopted to select a sample size of 480 respondents for the quantitative aspect of the study, while 36 participants were purposively selected for the qualitative aspect. The study examined the relationship between men's perception of the influence of antenatal clinic attendance on pregnancy outcome and their approval of wives' antenatal clinic attendance. It equally investigated the relationship between educational attainment and perception of non-attendance of antenatal clinic among women, and the relationship between requirement to obtain husband's permission and number of antenatal care attendance among women. Results showed that no relationships exist between men's perception of antenatal care attendance and their approval for wives' attendance of antenatal care facility. However, educational attainment among men was found to be positively related to their perception of antenatal clinic attendance. Similarly, test result showed a relationship between women's perception of antenatal care attendance and number of attendance, with $t(83.395)=7.718$, $p<0.001$.
\end{abstract}

Keywords Conjugal, Household, Lagos, Healthcare, Mortality

\section{Introduction}

Maternal health care services utilization is an important factor in reducing adverse pregnancy outcomes and pregnancy-related deaths for both mother and child. Despite this evidence, level of maternal health care utilization and attendance in many developing countries remain low, resulting in adverse pregnancy outcomes $[1,2]$. Adverse or negative pregnancy outcome arises when a pregnancy does not end in a live birth such as still birth or pregnancy wastage in form of miscarriage or abortion [3].

According to the World Health Organization (WHO), negative pregnancy outcomes rank among the most pressing reproductive health problems in the world [4]. Globally, an annual estimate of 600,000 women aged 15-49 years die of pregnancy related causes, with 99 percent coming from the developing world [5], and Nigeria alone accounts for over 10 percent of this total figure [2].

Though it has been observed that maternal and infant mortality rates in a country depend, to a large extent, on whether women have access to information, education, communication and the resources required to provide themselves and their infants with adequate care [3]; however, an important factor in women's access to maternal health services and attendance is the power dimension in the family or conjugal unit. In many families in Africa and Asia, men dominate the decision-making process; and many women will need the approval or permission of their husbands to attend maternal healthcare service centers. In fact, in some part of China, a situation as critical as caesarean procedures under emergency cannot be performed on a pregnant woman without the approval of her husband. This situation of waiting for husband's approval can endanger a woman's health and life during obstetrics emergencies $[6,8]$.

The import of men's support/approval of wives' use of maternal healthcare attendance is appreciated when the First-Delay in the Three-Delay framework for understanding factors contributing to mortality level in the context of obstetric emergencies is considered. In the Three-Delay framework, undue delays that can affect outcome of a pregnancy requiring emergency attention are (i) the decision to access care, (ii) the identification of, and transport to a medical facility, (iii) the receipt of timely, adequate and appropriate treatment [6]. The First-Delay 
comes in to play when a woman in need of obstetrics emergency or reproductive health has to obtain her husband's approval to access health-related facilities.

Essentially, for effective management and safe maternal and neonatal care, the WHO recommends that expectant mothers or pregnant women should have a minimum of three antenatal visits; have at least, two tetanus toxoid injections during pregnancy; or receive one tetanus toxoid injection during the pregnancy; and at least one in the three years preceding the pregnancy; and receive iron and folic acid tablets for 90 days or more [4]. The ability of a pregnant woman to obtain full antenatal care could be curtailed by a number of factors in the marital arena, such as gender power relation and the level of husband's support.

Although scholars have pointed out the role of education, religion and economic status in maternal healthcare service utilization [3], little or nothing has been done to interrogate the influence of husbands' disposition towards wives' use of maternal healthcare services. The aim of this study is to investigate the determinants of maternal healthcare utilization within conjugal context. The study focused on the following research questions: How does perception of the effect of not attending antenatal clinic on pregnancy outcome affect men's approval of their wives' antenatal clinic attendance? To what extent does men's educational attainment affect their perception of the effect of wives' non-attendance of antenatal clinic? What is the relationship between women's perception of the effect of not attending antenatal clinic and number of antenatal care attendance? To what extent does the requirement to obtain husbands' permission affect the number of antenatal care attendance among women?

\section{Materials and Methods}

The study was conducted in Shomolu Local Government Area (LGA), Lagos State, Nigeria, between March 10 and June 20, 2017. The LGA is made up of eight wards, out of which six wards were selected through simple random probability technique. The selected wards included Ward A, Onipanu; Ward B, Bashua; Ward D, Orile/Alade; Ward E, OkesunaAlase; Ward F, Bajulaiye; and Ward H, Fadeyi/Igbobi.

The study involved both quantitative and qualitative approaches. According to 2006 national population census in Nigerian, the population of married people in Lagos State was $3,293,811$; comprising 1,611,331 males and 1,682, 480 females. From this figure, a sample size of 480 respondents was scientifically determined by using Yaro Yamane (1967) formula for sample size determination. Essentially, the computation of the formula and procedure yielded a sample size of 399.87 , which was approximated to 400 . However, the resulting sample size was increased by 20 percent, so that if there were unreturned or unreliable questionnaires, it would not significantly affect the sample size. This process brought the sample size to 480 respondents.

At the quantitative level, cross-sectional survey was adopted, while In-Depth Interview (IDI) was used at the qualitative level. A combination of simple random and systematic sampling techniques was adopted to select the respondents (comprising 240 males and 240 females) for the quantitative aspect of the study. The procedures included using simple random sampling technique to select four streets from each of the selected wards in the LGA. This was followed by house-listing, that is, the number of occupied buildings in each street was determined and listed. Next, a systematic sampling technique was used to select some buildings in each street. Overall, 480 houses were targeted. Thus, 20 buildings or compounds were systematically selected from each of the streets. At the level of compounds, the number of households with married individuals in each compound was determined. This was followed by the selection of one household in each compound through simple random technique. Afterwards, an eligible respondent was selected from the household. An eligible respondent at the household level was a man whose wife had experienced pregnancy, or a woman who had experienced pregnancy. Male and female were selected in alternate sequence.

On the other hand, purposive sampling technique was used to select 36 participants for the qualitative aspect of the study. The purposive sampling technique enabled the identification and selection of eligible subjects in the qualitative analysis. Eligible subjects were ever-married men and women who must have experienced pregnancy at the time of the survey.

Survey questionnaire was the pricipal instrument used in the study. Two separate questionnaires were designed for male and female in order to be able to address and elicit sex-specific questions and information. The questionnaire was an admixture of both close-ended and open-ended questions. The questionnaire for male respondents was structured into two sections, while that of the female respondents was structured into three sections. The instruments were pretested to identify possible errors in the questionnaire to ensure that questions were in logical sequence, comprehensible, appropriate, meaningful and clear to research subjects. After the pretest, the identified inadequacies were addressed before the actual study was carried out. Three research assistants (RAs) were recruited for the survey and were trained for three days to familiarize them with the contents of the instrument. The training involved a theoretical aspect on how to conduct interview and observe ethical guidelines, and a practical mock interview session supervised by the three members of the research team. Data were analyzed by the Statistical Package for Social Sciences (SPSS) version 20. Descriptive and inferential techniques were the principal statistical techniques adopted in the analysis. The 
descriptive statistic included percentages and means; while the inferential analytical techniques adopted to test the hypotheses were Student $t$-test and Binary logistic regression model. The hypotheses were tested at alpha level of 0.05 (i.e., $\alpha=0.05$ ).

\section{Delimitation and Limitation of the Study}

The study was delimited to conjugal context and focused on variables such as perception of antenatal care attendance and men's approval of their spouses' usage of antenatal facilities. In the study, approval was conceptualized as whether the female partner or wife requires her husband's permission to attend antenatal care. These variables are in important in understanding the role of power imbalance on access to antenatal care among women, especially in patriarchal societies like Nigeria. However, the study has limitation. One major weakness of the study was the inability to account for the role of intervening variables such as cost of healthcare services, past family experience with using prenatal care and pregnancy outcomes among others, in the analysis. Some of these variables may exert some influence on subjects' perception of use of antenatal care services and number of attendance of antenatal facility.

\section{Results and Discussion}

This segment is concerned with analysis of data and presentation of results of test of hypotheses. Four hypotheses were formulated and tested in the study. They include: (i) Perception of not attending antenatal clinic among men does not affect their approval of wives' antenatal clinic attendance. (ii) There is no relationship between educational attainment among men and perception of the effect of wives' non-attendance of antenatal clinic. (iii) Women's perception of the effect of not attending antenatal clinic is not significantly related to their number of antenatal care attendance. (iv) There is no relationship between the requirement to obtain husband's permission to attend antenatal clinic and number of antenatal care attendance among women. The variables were subjected to bivariate and multivariate analyses, depending on their level of measurement. The predictor variables in the first and second hypotheses are men's perception of the effect of their wives not attending antenatal clinic, and men's level of education; while their respective outcome variables are wives' requiring approval to attend antenatal clinic, and perception of the effect of not attending antenatal clinic on pregnant women. Each outcome variable was dichotomous (i.e., binary or $0-1$ ) and was related to a set of categorical predictors.

\section{Background Characteristics of Respondents}

Background characteristics such as age, education, employment status and religion of individuals are important determinants of people's behavior. Table 1 shows overall view of key background characteristics of survey respondents.

Table 1. Socio-Demographic Information of Respondents

\begin{tabular}{|c|c|c|}
\hline Variables & Frequency & Percent \\
\hline \multicolumn{3}{|c|}{ Age Group } \\
\hline $20-29$ & 39 & 8.1 \\
\hline $30-39$ & 127 & 26.5 \\
\hline $40-49$ & 181 & 37.7 \\
\hline $50-59$ & 80 & 18.3 \\
\hline $60-69$ & 38 & 7.9 \\
\hline $70-79$ & 3 & 0.6 \\
\hline No Response & 4 & 0.8 \\
\hline Total & 480 & 100.0 \\
\hline \multicolumn{3}{|c|}{ Marital Status } \\
\hline Single & 13 & 2.7 \\
\hline Married & 423 & 88.1 \\
\hline Widowed & 18 & 3.8 \\
\hline Separated & 21 & 4.4 \\
\hline Divorced & 2 & 0.4 \\
\hline No Response & 3 & 0.6 \\
\hline Total & 480 & 100.0 \\
\hline \multicolumn{3}{|c|}{ Religious Affiliation } \\
\hline Christianity & 231 & 48.1 \\
\hline Islam & 217 & 45.2 \\
\hline Traditional & 30 & 6.3 \\
\hline None & 2 & 0.4 \\
\hline Total & 480 & 100.0 \\
\hline \multicolumn{3}{|c|}{ Education } \\
\hline None & 7 & 1.5 \\
\hline Primary & 38 & 7.9 \\
\hline Secondary (JSS) & 13 & 2.7 \\
\hline Secondary (SSS) & 252 & 52.5 \\
\hline Tertiary & 170 & 35.4 \\
\hline Total & 480 & 100.0 \\
\hline \multicolumn{3}{|c|}{ Employment Status } \\
\hline Employed & 453 & 94.4 \\
\hline Unemployed & 15 & 3.1 \\
\hline No Response & 12 & 2.5 \\
\hline Total & 480 & 100.0 \\
\hline
\end{tabular}

In this study, the age of respondent was the completed age or age at last birth date. Table 1 above shows the distribution of age group and employment status of respondents. Data from the quantitative survey captured respondents between ages 20 and 79 years. The highest age concentration constituted those between 40 and 49 years and accounts for 37.7 percent of the respondents in the study. Furthermore, data in the table show that about 97.3 percent of the respondents were ever married. This confirms the near universality of marriage among adults in the Nigerian society.

The table reveals further that majority of the respondents in the study location were employed at the time of the study. The level of unemployment shown here seems lower than the 19.7 percent recorded at the national level [9]. This may be attributed to the fact that some people who are self-employed are sometimes reported as unemployed [10]. 
Table 2. Binary Regression Coefficients and Odds Ratio Showing the Effect of Explanatory Variable on Men's Likelihood to approve their Wives' Antenatal Clinic Attendance

\begin{tabular}{|c|c|c|c|c|c|c|}
\hline \multirow{2}{*}{ Variables } & \multirow{2}{*}{ Coefficient } & \multirow{2}{*}{ S.E } & \multirow{2}{*}{ Sig. } & \multirow{2}{*}{ Odds Ratio } & \multicolumn{2}{|c|}{$95 \%$ CI } \\
\hline & & & & & Lower & Upper \\
\hline \multicolumn{7}{|c|}{ Perception on Effect of Non-Attendance } \\
\hline Positive & 0.290 & 0.381 & 0.447 & 1.336 & 0.633 & 2.820 \\
\hline Negative (RC) & & & & 1 & & \\
\hline \multicolumn{7}{|c|}{ Level of Education } \\
\hline Primary (RC) & & & & 1 & & \\
\hline Secondary & 1.120 & 0.772 & 0.147 & 3.065 & 0.274 & 3.928 \\
\hline Tertiary & 0.586 & 0.798 & 0.463 & 1.797 & 0.376 & 8.596 \\
\hline \multicolumn{7}{|c|}{ Age Group } \\
\hline $20-29(\mathrm{RC})$ & & & & 1 & & \\
\hline $30-39$ & -1.281 & 0.715 & 0.073 & 0.278 & 0.068 & 1.128 \\
\hline $40-49$ & -2.067 & 0.704 & 0.003 & 0.127 & 0.032 & 0.503 \\
\hline $50-59$ & -2.266 & 0.763 & 0.003 & 0.104 & 0.023 & 0.462 \\
\hline $60-69$ & -2.657 & 0.985 & 0.007 & 0.070 & 0.010 & 0.483 \\
\hline $70>$ & -1.099 & 1.384 & 0.427 & 0.333 & 0.022 & 5.027 \\
\hline \multicolumn{7}{|c|}{ Religion } \\
\hline Christianity (RC) & & & & 1 & & \\
\hline Islam & 0.011 & 0.344 & 0.973 & 1.011 & 0.516 & 1.984 \\
\hline Traditional & 0.517 & 0.640 & 0.419 & 1.676 & 0.479 & 5.871 \\
\hline \multicolumn{7}{|c|}{ Employment Status } \\
\hline Employed (RC) & & & & 1 & & \\
\hline Unemployed & 2.640 & 0.422 & 0.993 & 1.625 & 1.341 & 2.480 \\
\hline
\end{tabular}

$\mathrm{RC}=$ Reference Category, $\mathrm{CI}=$ Confidence Interval.

Table 2 above shows a binary logistics model adopted to predict the likelihood of men wanting their wives to obtain approval before attending antennal clinic. In the model, the key variable is perception of the consequences of not attending antenatal clinic. The model revealed no relationship between the independent and dependent variables. Among other categorical variables included in the model, only ages of respondents were found to be related to requirement of husband's approval to attend antenatal healthcare centre. Nonetheless, the relationship is inverse and not constant across all the categories; only among the third, fourth and fifth categories. In other words, men between ages 40-49 are 0.127 times less likely to require their wives to obtain permission before attending antenatal healthcare centre than those between 20-29 years of age; while those between ages 50-59 years are 0.104 times less likely to require their wives to obtain approval. Similarly, relative to men in age group 20-29, those who are 60 years and above are 0.070 less likely to require an approval for their spouses before attending antenatal clinic.

However, data from the qualitative study on the relationship between men's perception of the effect of not attending antenatal clinic by wives and approval of wives' use of antenatal healthcare facilities indicate that perception on use of antenatal clinic could be a factor in the approval of wives' use of antenatal facilities among a segment of male population. For instance, one of the participants who stated that not attending antenatal clinic by a woman does not mean a woman cannot give birth safely at home, noted as follows:

A man is the head of the family, and his wife is not supposed to go out without his permission whether the woman is pregnant or not (IDI/Male/Alade Community/13/5/2017).

Although it is inadequate to generalize that negative perception about antenatal service usage among men is likely to adversely affect men's approval of their wives' attendance of antenatal clinic on the basis of the revelation of a participant in a qualitative study, the information is an indication that perception of use of antenatal clinic tends to influence men's approval of their wives' antenatal clinic attendance in some conjugal units. 
Table 3. Binary Regression Coefficients and Odds Ratio Showing the Effect of Explanatory Variable on Perception of Effects of Non-Attendance of Antenatal Clinic among Men

\begin{tabular}{|c|c|c|c|c|c|c|}
\hline \multirow{2}{*}{ Variables } & \multirow{2}{*}{ Coefficient } & \multirow{2}{*}{ S.E } & \multirow{2}{*}{ Sig. } & \multirow{2}{*}{ Odds Ratio } & \multicolumn{2}{|c|}{$95 \%$ CI } \\
\hline & & & & & Lower & Upper \\
\hline \multicolumn{7}{|c|}{ Level of Education } \\
\hline Primary (RC) & & & & 1 & & \\
\hline Secondary & 0.596 & 0.331 & 0.071 & 1.815 & 0.949 & 3.470 \\
\hline Tertiary & 1.539 & 0.513 & 0.003 & 4.659 & 1.703 & 2.744 \\
\hline \multicolumn{7}{|c|}{ Age Group } \\
\hline $20-29(\mathrm{RC})$ & & & & 1 & & \\
\hline $30-39$ & 0.071 & 0.729 & 0.923 & 1.073 & 0.257 & 2.482 \\
\hline $40-49$ & 0.410 & 0.685 & 0.549 & 1.509 & 0.393 & 4.774 \\
\hline $50-59$ & 0.804 & 0.706 & 0.255 & 2.235 & 0.560 & 4.681 \\
\hline $60-69$ & 0.901 & 0.787 & 0.252 & 2.462 & 0.527 & 3.843 \\
\hline $70-79$ & -1.817 & 1.422 & 0.718 & 2.892 & 0.346 & 1.459 \\
\hline \multicolumn{7}{|c|}{ Employment Status } \\
\hline Employed & 0.662 & 1.105 & 0.549 & 1.939 & 1.222 & 2.924 \\
\hline Unemployed (RC) & & & & 1 & & \\
\hline \multicolumn{7}{|c|}{ Marital Status } \\
\hline Single & -1.021 & 1.133 & 0.346 & 0.107 & 1.713 & 3.298 \\
\hline Married & -0.754 & 0.624 & 1.457 & 0.227 & 0.138 & 1.600 \\
\hline Widowed & -0.511 & 1.057 & 0.629 & 0.600 & 0.176 & 2.760 \\
\hline Separated(RC) & & & & 1 & & \\
\hline \multicolumn{7}{|c|}{ Religion } \\
\hline Christianity (RC) & & & & 1 & & \\
\hline Islam & 0.731 & 0.319 & 0.022 & 2.077 & 1.112 & 3.880 \\
\hline Traditional & 2.516 & 0.634 & 0.000 & 3.375 & 3.571 & 4.880 \\
\hline
\end{tabular}

RC: Reference Category

Table 3 is a binary regression model designed to predict the influence of categorical variables such as education, age, employment status, marital status and religion on perception of the effect of pregnant women not attending antenatal clinic. In the model, education was included as key variables. The objective was to examine if the level of educational attainment shapes men's perception on the effect of maternal healthcare utilization of their wives. The result shows that, although educational attainment was found to be related to the dependent variable, only the third category was found to be significant such that men with tertiary level of education are 4.659 times more likely to perceive non-attendance of maternal healthcare as a problem that can affect pregnancy outcome.

Among other variables included in the model, religion was found to be an important predictor to how men perceived their wives' non-attendance of maternal healthcare centre. The model shows that traditional religion followers are 3.375 times more likely than Christians to see non-attendance of maternal healthcare centre among women as a problem that can adversely affect pregnancy outcome; while Muslims are 2.077 times more likely to perceive not going to maternal clinic as a possible cause of adverse pregnancy outcome.

Theoretically, it is assumed that knowledge of the negative implications of low level of use of maternal health facilities among men can enhance their support for their wives' visits and use of maternal health facilities. Existing evidence suggests that in Nigeria, there is a low level of use of maternal healthcare services [1], and a significant number of birth deliveries were unsafe [10]. Unsafe deliveries are classified as deliveries not conducted either in a medical facility or home deliveries not assisted by a doctor, nurse or lady health visitor (LHV)/ auxiliary nurse midwife (ANM) or other health professionals [3]. In many developing countries, there are still indications that many pregnant women prefer to patronize traditional birth attendance (TBA). This may jeopardize the health of the mother and child if there are obstetrics complications or prolonged labour during childbirth that may require professional attention. 
Table $4 \mathrm{a}$ and $\mathrm{b}$ show a $t$-test result on perception of the effect of not attending antenatal care centre and number of antenatal care attendance among women in the study. The $p$-value of Levene's test indicated $p<0.001$, meaning that the null hypothesis of Levene's test is rejected. Accordingly, equal variance not assumed in the test shows that there is a statistically significant difference between the mean number of antenatal care attendance of women with positive perception of antenatal care attendance $($ Mean $[\mathrm{m}]=3.76$, Standard deviation $[\mathrm{s}]=0.544$, and women with negative perception of antenatal care attendance $(\mathrm{m}=2.40 . \mathrm{s}=1.480, t(83.395)=7.718$, $p<0.001$.)

A similar conclusion was found in the qualitative data on this objective: A participant who stated that she regularly visited antenatal clinic stated thus:

Hospital is the best place to go when you are pregnant. Those women who go and stay in the church or visit *alagbo are risking their lives (IDI/female/Bajulaiye Community/4/5/2017).

*The Yoruba concept of individuals who prepare and dispense local mixtures and concoctions to service users.
In the study, women's perception of the effect of antenatal care attendance was measured at two levels: positive and negative perceptions. Positive perception was operationalised as the belief that not attending antenatal care will adversely affect pregnancy outcome; while negative perception is a construct which implied that not attending antenatal care has no negative effect on pregnancy outcome. By this finding, it means women who believed that not attending antenatal care facility during pregnancy can endanger a woman's obstetrics condition, tend to attend maternal healthcare centre than their counterparts who believed otherwise.

Table $5 \mathrm{a}$ and $\mathrm{b}$ indicate the result of $t$-test statistics on the relationship between the requirement to obtain husband's permission and number of antenatal care attendance among women. The test revealed that there is no statistically significant difference between the mean number of antenatal attendance by women who required permission from their husbands (Mean $[\mathrm{m}]=3.51$, Standard deviation $[\mathrm{s}]=0.938)$ and the mean number of antenatal attendance by women who do not require permission from their husbands $(\mathrm{m}=3.47, \mathrm{~s}=1.319, t(70.512)=1.675, p=$ $0.098>0.05$ alpha $(\alpha)$ level.)

Table 4. Distribution of perception on effect of non-attendance of antenatal care centre and number of antenatal care attendance

(a) Group Statistics

\begin{tabular}{|l|c|c|c|c|}
\hline \multirow{2}{*}{ Number of Antenatal Care Attendance } & Perception on Non-Attendance & N & Mean & Std. Deviation \\
\cline { 2 - 5 } & Std. Error Mean \\
\cline { 2 - 5 } & Negative & 162 & 3.76 & 0.544 \\
\hline
\end{tabular}

(b) Independent Sample Test

\begin{tabular}{|c|c|c|c|c|c|c|c|c|c|c|}
\hline & & \multicolumn{2}{|c|}{$\begin{array}{c}\text { Levene's Test for } \\
\text { Equality of variance }\end{array}$} & \multicolumn{7}{|c|}{$t$-Test for Equality on Means } \\
\hline & & \multirow{2}{*}{$\mathrm{F}$} & \multirow{2}{*}{ Sig. } & \multirow{2}{*}{$\mathrm{T}$} & \multirow{2}{*}{ Df } & \multirow{2}{*}{$\begin{array}{c}\text { Sig. } \\
\text { (2-tailed) }\end{array}$} & \multirow{2}{*}{$\begin{array}{l}\text { Mean } \\
\text { Diff. }\end{array}$} & \multirow{2}{*}{$\begin{array}{l}\text { Std. } \\
\text { Error Diff. }\end{array}$} & \multicolumn{2}{|c|}{$95 \% \mathrm{CI}$} \\
\hline & & & & & & & & & Lower & Upper \\
\hline \multirow{2}{*}{$\begin{array}{c}\text { Number of } \\
\text { Antenatal Care } \\
\text { Attendance } \\
\end{array}$} & Equal variance assumed & 521.475 & .000 & 10.305 & 235 & 0.000 & 1.359 & 0.132 & 1.099 & 1.619 \\
\hline & Equal variance not assumed & & & 7.718 & 83.395 & 0.000 & 1.359 & 1.176 & 1.009 & 1.710 \\
\hline
\end{tabular}

Table 5. Distribution on Husband's Permission and number of antenatal care attendance

(a) Group Statistics

\begin{tabular}{|c|c|c|c|c|c|}
\hline & Husband's Permission & $\mathbf{N}$ & Mean & Std. Deviation & Std. Error Mean \\
\hline \multirow{2}{*}{ Number of Antenatal Care Attendance } & Need Permission & 173 & 3.51 & 0.938 & 0.071 \\
\hline & Permission not Required & 54 & 3.47 & 1.319 & 0.179 \\
\hline
\end{tabular}

(b) Independent Sample Test

\begin{tabular}{|c|c|c|c|c|c|c|c|c|c|c|}
\hline & & \multicolumn{2}{|c|}{$\begin{array}{c}\text { Levene's Test for } \\
\text { Equality of variance }\end{array}$} & \multicolumn{7}{|c|}{$t$-Test for Equality on Means } \\
\hline & & \multirow{2}{*}{$\mathrm{F}$} & \multirow{2}{*}{ Sig. } & \multirow{2}{*}{$\mathrm{T}$} & \multirow{2}{*}{ Df } & \multirow{2}{*}{$\begin{array}{c}\text { Sig. } \\
\text { (2-tailed) }\end{array}$} & \multirow{2}{*}{$\begin{array}{l}\text { Mean } \\
\text { Diff. }\end{array}$} & \multirow{2}{*}{$\begin{array}{l}\text { Std. } \\
\text { Error Diff. }\end{array}$} & \multicolumn{2}{|c|}{$95 \% \mathrm{CI}$} \\
\hline & & & & & & & & & Lower & Upper \\
\hline \multirow{2}{*}{$\begin{array}{c}\text { Number of } \\
\text { Antenatal Care } \\
\text { Attendance }\end{array}$} & Equal variance assumed & 20.743 & .046 & 1.995 & 225 & 0.067 & 0.323 & 0.162 & 1.004 & 1.643 \\
\hline & Equal variance not assumed & & & 1.675 & 70.512 & 0.098 & 0.323 & 0.193 & -0.062 & 1.709 \\
\hline
\end{tabular}


Over the years, social researchers have been concerned with attempts at interpreting factors that influence the utilization of maternal healthcare facilities, especially in developing countries with low level of maternal healthcare attendance with its associated high rate of maternal and child mortality $[2,11]$. Records show that in sub-Saharan Africa, every day, 739 women die from complications of pregnancy and childbirth, which is about 270,000 deaths every year [12]. Many of these deaths were as a result of lack of adequate antenatal and postnatal healtcare service attendance [3].

Efforts have been made in earlier work to investigate the roles of factors such as socio-economic status and distance from home to maternal healthcare centre [13]. This study investigated the determinants of maternal healthcare service utilization within conjugal context. The objective was to examine if perception of the effect of antenatal clinic attendance on pregnancy outcome among men affects their approval of their wives' antenatal clinic attendance; and whether there is a relationship between educational attainment among men and their perception of the effect of wives' non-attendance of antenatal clinic. It also examined if women's perception of the effect of not attending antenatal clinic affect their antenatal care attendance; as well as whether there is a relationship between the requirement to obtain husband's permission and number of antenatal care attendance among women. In many families in Nigeria, women must obtain permission from their husbands before going out.

Findings indicate that perception of the effect of not attending antenatal clinic by husbands is not related to the requirement for approval before their wives can attend antenatal clinic. Nonetheless, educational attainment among men was found to be positively related to men's perception of the impact of non-attendance of antenatal centre by women.

Women were also focused on as a specific group. The test result on women's perception of the effect of non-attendance of antenatal care centre and number of antenatal care attendance showed a statistically significant difference between the mean number of antenatal care attendance of women with positive perception of antenatal care attendance and those with negative perception of antenatal care attendance. However, requirement for husband's approval was not found to be related with number of antenatal care attendance among women.

\section{Conclusion and Recommendations}

This study examined the dynamics of antenatal healthcare attendance among women in conjugal context. A major factor in positive pregnancy outcome is seeking professional obstetrics attention which is expressed by adequate antenatal and postnatal care attendance. Existing evidence indicates that there is a low level of maternal healthcare attendance in Nigeria making the country to be the leading contributor to maternal death figures in sub-Saharan Africa. On the basis of the findings, it is recommended that efforts should be geared towards increasing awareness about the risks of low antenatal and postnatal care attendance among pregnant women. Some women tend to patronize traditional birth attendants (TBA) and herbalists for maternal care. Unfortunately, many of such places lack the skill and equipment for handling obstetrics emergencies and complications, putting the life of those who patronize them at risk.

Furthermore, there is need for greater male involvement in women's maternal care need. Strong patriarchal ideology in Nigerian society makes it difficult for many men to contribute significantly to alleviate their wives' maternity condition. There in need for a change in attitude in this regard to ease women's obstetrics burdens and challenges.

\section{REFERENCES}

[1] Akinlo A, Bisiriyu B, Esima O. Influence of use of maternal health care on postpartum contraception in Nigeria. DHS Working Papers. Maryland, USA: ICF International; 2013.

[2] Babalola S, Fatusi A. Determinants of use of maternal health services in Nigeria: Looking beyond the household factors. $B M C$. Available online:

https://www.biomedcentral.com/articles/2009/10.1186/147 $1-2393-9-43$ [Retrieved $24^{\text {th }}$ June 242016 ].

[3] Singh PH, Rai R K, Alagarajan M, Singh L. Determinants of maternal care services utilization among married adolescents in rural India. Available from: http://www.s31666.doi:10.1371/journal.pone.0031666/201 2/PloSONE7/2/ [Accessed $15^{\text {th }}$ November 2015].

[4] World Health Organization. Provision of effective antenatal care: Integrated management of pregnancy and child birth, Standard for Maternal and Neonatal Care (1.6), Making Pregnancy Safer, Geneva, Switzerland. 2006. Available online:

http://www.who.int/making_pregnancy_safer/publications/s tandards 1.6N.pdf.[Accessed 23rd July 2017].

[5] Population Reference Bureau. World Population Data Sheet. Washington: PRB; 2016.

[6] Calvello EJ, Skog AP, Tenner AG, Wallis LA. Applying the lessons of maternal mortality reduction to global emergency health. Bulleting of the World health Organization. Deparment of Emergency Medicine, University of Maryland, USA; 2015.

[7] Lozano R, Wang H, Foreman KJ, Rajaratnam JK, Naghavi M, Marcus JR, et al. Progress towards Millennium Development Goals 4 and 5 on maternal and child mortality: An updated systematic analysis. Lancet. 2011; 378(9797):113-219. Available from doi:1165/1.113.9780.

[8] Nyamtema AS, Urassa DP, Van Roosmalen J. Maternal 
health interventions in resource limited countries: A systematic review of packages, impacts and factors for change. BMC Pregnancy Childbirth. 2011;11(1):30-38.

[9] National Bureau of Statistics.

Unemployment/under-employment report, Q3 2016; 2016. Available from: www.national/stat.ng.gov. [Accessed 3 August 2016].

[10] National Population Commission \& ICF International. Nigeria Demographic and Health Survey 2013. Abuja and Maryland: NPC \& ICF International; 2014.
[11] Ashraf N, Field E, Voena A. Understanding male fertility preferences in Zambia. Lusaka: Abdul Latif Jameel Poverty Action Lab (J-PAL); 2011.

[12] Awe OO. Population, Family Planning and HIV/AIDS in Sub-Saharan Africa. Journal of Sociological, Psychological and Anthropology in Practice. 2009;1(3): 134-144. 13.571 4.8809

[13] Zerai A, Tsui AO. The relationship between prenatal care and subsequent modern contraceptive use in Bolivia, Egypt and Thailand. African Journal of Reproductive Health.2001;5(2):68-82. 